\title{
Survival of undersized plaice (Pleuronectes platessa) discarded in the bottom otter trawl and Danish seine mixed fisheries in Skagerrak
}

Noack, Thomas; Savina, Esther; Karlsen, Junita Diana

Published in:

Marine Policy

Link to article, DOI:

10.1016/j.marpol.2020.103852

Publication date:

2020

Document Version

Peer reviewed version

Link back to DTU Orbit

Citation $(A P A)$ :

Noack, T., Savina, E., \& Karlsen, J. D. (2020). Survival of undersized plaice (Pleuronectes platessa) discarded in the bottom otter trawl and Danish seine mixed fisheries in Skagerrak. Marine Policy, 115, [103852].

https://doi.org/10.1016/j.marpol.2020.103852

\section{General rights}

Copyright and moral rights for the publications made accessible in the public portal are retained by the authors and/or other copyright owners and it is a condition of accessing publications that users recognise and abide by the legal requirements associated with these rights.

- Users may download and print one copy of any publication from the public portal for the purpose of private study or research.

- You may not further distribute the material or use it for any profit-making activity or commercial gain

- You may freely distribute the URL identifying the publication in the public portal 


\section{Highlights}

- Fish caught by the trawler showed lower survival than those caught by the seiner.

- Air exposure was the most important factor of discard survival for the trawler.

- For the seiner, bottom temperature was an additional important determinant. 


\section{Keywords}

2 Captivity experiment; demersal fisheries; discard ban; discard survival analysis; landing obligation

\section{Abstract}

4 The landing obligation of the new Common Fisheries Policy includes a "high survival"-exemption,

5 which allows to continue discarding of fish with scientifically proven high chances to survive the

6 process of capture, handling and release. This study presents survival rates of undersized plaice

7 (Pleuronectes platessa) caught by two commercial fishing vessels targeting plaice in Skagerrak

8 during the summer, a bottom otter trawler and a Danish anchor seiner. Instead of being discarded, the

9 fish were assessed and monitored in on-land observation tanks for 14 days. For each gear, a Weibull

10 mixture model was fitted to the data to estimate survival probabilities, including the uncertainties

11 from the haul selection and conditions of the captivity experiment, and to determine which biological,

12 environmental and operational factors influence survival. Generally, fish caught by the trawler

13 showed lower survival (44\%, 95\%-confidence interval: $37-52 \%)$ than those caught by the seiner

$14(78 \%, 95 \%$-confidence interval: $67-87 \%)$. Air exposure was found to be the most important factor in

15 determining survivability of fish discarded from the trawler. For the seiner, bottom temperature was

16 identified as an additional important determinant. 
1 Survival of undersized plaice (Pleuronectes platessa) discarded in the bottom otter trawl

2 and Danish seine mixed fisheries in Skagerrak

3 Thomas Noack $^{1^{* \dagger}}$, Esther Savina ${ }^{1 \dagger}$, Junita D. Karlsen ${ }^{1}$

$4{ }^{1}$ Technical University of Denmark, National Institute of Aquatic Resources, North Sea Science Park, 5 PO Box 101, DK-9850 Hirtshals, Denmark

$6 \quad{ }^{*}$ Corresponding author: thomas.noack@thuenen.de

$7 \quad$ Equal authorship 


\section{Introduction}

Unaccounted fishing mortality is recognized as an important determinant in the management

3 of bycatch, and discard survival studies have been conducted in commercial and recreational fisheries

4 around the world [1-3]. Recently, the European Common Fisheries Policy (CFP) landing obligation has

5 led to an increased interest in documenting discard survival rates. To facilitate the implementation of

6 the landing obligation, i.e., the obligation to land all catches of regulated species, the need for some

7 flexibility was recognized by EU co-legislators [4]. The high survival exemption was included to allow

8 discarding of regulated species that demonstrated a high chance of surviving the process of capture,

9 handling and discarding, based on scientific evidence [5,6]. The main reason for such an exemption was

to avoid landing and eventually killing individuals, which otherwise would have survived being discarded. However, exemptions are increasingly sought as fish below Minimum Conservation Reference Size (MCRS) count against the quota, which would else be available for more valuable catches. Furthermore, retaining individuals that were simply discarded increases handling times (especially for mixed fisheries), limits storing capacities (especially for small and intermediate-sized vessels, i.e., under $24 \mathrm{~m}$ ), and introduces challenges in selling this less valuable part of the catch as new sale channels need to be established [7,8]. As specified in the regulation [4], the survival rates examined for a potential high survival exemption should take into account the characteristics of the gear, fishing practices and ecosystem. The prioritization of species and fisheries to investigate has been influenced by the potential for high survival, based on existing knowledge, the discard rates, and the likely timing for introduction under the landing obligation $[8,9]$.

Two widely used fishing gears in Denmark are bottom otter trawls and Danish anchor seines. Both gears are operated in Skagerrak (ICES area IIIa) and participate in the demersal mixed fisheries. The trawlers target a mix of species, e.g. Norway lobster (Nephrops norvegicus), Atlantic cod (Gadus morhua), European plaice (Pleuronectes platessa) and saithe (Pollachius virens). The most important target species for seiners is plaice, but other species like witch flounder (Glyptocephalus cynoglossus), cod and haddock (Melanogrammus aeglefinus) are also targeted. Both fisheries catch undersized regulated species and are therefore affected by the landing obligation [10]. In Skagerrak, an average 
(weight) of $24 \%$ (range: $11-40 \%$ ) of the total annual catches of plaice in the mixed bottom trawl fishery using mesh sizes 90-119 mm were discarded in 2011-2016, while it was 8\% (range: 4-14\%) when caught by Danish seiners (data from the EU Data Collection Framework, Danish Agrifish Agency, Ministry of Environment and Food of Denmark). Plaice has been subject to several studies in Europe, which investigated survival of discards from bottom otter trawls $[9,11-16]$, beam trawls $[17,18]$ and pulse beam trawls [19]. Uncorrected for any effects of predation, research-related handling including tagging for identification of individuals or holding conditions, these studies found survival of undersized plaice to vary from 0 to $86 \%$, depending on biological (e.g. fish size, vitality), environmental (e.g. water temperature, air temperature) and operational factors (e.g. fishing gear, haul duration, air exposure duration). The Danish bottom otter trawlers using 90-119 mm mesh size in Skagerrak range in length from 10 to $35 \mathrm{~m}$ (mean: $18 \mathrm{~m}$ ) and in power from 67 to $901 \mathrm{~kW}$ (mean: $253 \mathrm{~kW}$; Ministry of Environment and Food of Denmark, Danish Agrifish Agency). In Skagerrak, discard survival of plaice has previously been investigated in the small-scale otter trawl demersal fishery targeting plaice or Norway lobster (commercial vessels of length 11.8 and $11.7 \mathrm{~m}$, power 92 and $125 \mathrm{~kW}$, and mesh size 105 and $90 \mathrm{~mm}$, respectively) $[13,15]$. When targeting plaice, the discard survival for plaice from this study was $88.9 \%$ (95\%-CI: 83.7-92.9\%) [13]. As smaller vessels use smaller gears, catches are likely to be lower compared with larger vessels, and so are handling time and air exposure. Air exposure affects discard survival rates with higher survivability for individuals with limited air exposure during the catch sorting process $[13,14,19,20]$. The present study aimed at collecting additional evidence on discard survival of plaice representative (i.e., average size and power) of the wider segment of the Danish otter trawl fleet.

No published studies on discard survival exist for Danish seiners. Bottom otter trawlers and Danish seiners are managed together by European legislations, but have very different fishing procedures and gears. Fishing with a Danish seine begins by dropping an anchor, to which a set of marker buoys and the first seine rope is attached. After setting the seine net, the second rope is laid out, and the vessel returns to the anchor buoys, and begins hauling the seine ropes (for further description, see [20]). Danish seines use lighter gears and, in contrast to trawling, fish spend only the last period of 
the haul inside the net [21]. Both aspects lead to a reduced risk of fish injury, thus survival of discarded fish is expected to differ between the gears [21].

The aim of this study was to estimate the survival probability of plaice below MCRS $(27 \mathrm{~cm})$ discarded from a Danish bottom otter trawler and a Danish seiner of average size and power with respect to the demersal mixed fishery targeting plaice in Skagerrak. The study was designed to inform the Danish authorities about survivability of plaice discarded in the bottom otter trawlers and Danish seiners mixed fishery in the North Sea and Skagerrak. Discard of plaice above MCRS is believed to be minimal since the fishery is not quota limited [15]. Additional to the effect of fishing gear, the effects of biological (fish size), operational (haul duration, catch weight, air exposure, depth) and environmental factors (air, surface sea water and bottom sea water temperatures, weather conditions) on survival of discarded plaice were investigated.

\section{Material and Methods}

\subsection{Study site and vessel specifications}

Fishing was conducted in Skagerrak, north of Hirtshals (Fig. 1). The southern part of the Skagerrak, where the trials took place, is characterized by relatively shallow waters $(<80 \mathrm{~m})$. At $30 \mathrm{~m}$ depth, maximum temperatures are reached in October-November, contrary to the surface where the maximum occurs in July-August. Minimum temperatures are reached in March-April, one month later than at the surface. Subsurface temperature variabilities during summer on the Danish slope at $50 \mathrm{~m}$ depth are influenced by local weather conditions [22]. Bottom temperature can be as low as $5^{\circ} \mathrm{C}$ in Danish coastal waters in winter [22]. Air temperature range on average from $1.1^{\circ} \mathrm{C}$ in February to $17.6^{\circ} \mathrm{C}$ in July (last 10 years in Denmark, DMI).

The trawler S84 "Ida-Katrine" had a LOA of $15.1 \mathrm{~m}$ and an engine power of $221 \mathrm{~kW}$. In a twin rig, it was fishing with two identical trawls (420 meshes of $80 \mathrm{~mm}$ around the fishing circle) with two $8 \mathrm{~m}$ long $96 \mathrm{~mm}$ diamond mesh codends with $270 \mathrm{~mm}$ diamond mesh escape windows (SELTRA). The codends consisted of 100 open meshes in circumference and were made of $3 \mathrm{~mm}$ double twine polyethlyene (PE) knotted netting (escape window: $5 \mathrm{~mm}$ single PE twine). The Danish seiner S15 
"Vera-Marie" had a LOA of $16.1 \mathrm{~m}$ and an engine power of $142 \mathrm{~kW}$. It was fishing with a seine net that had 360 meshes around the fishing circle (nominal mesh size: $120 \mathrm{~mm}$ ). The $7 \mathrm{~m}$ long codend was made of $4 \mathrm{~mm}$ double twine PE knotted netting with a nominal mesh size of $125 \mathrm{~mm}$ (diamond) and had 97 open meshes in circumference. The vessels were chosen in collaboration with the Danish Fishermen Producer Organisation to represent the fleet as much as possible. Both vessels had a length and power close to the average of the respective fleets operating in Skagerrak, i.e., $18 \mathrm{~m}$ and $253 \mathrm{~kW}$ for the trawlers, $17 \mathrm{~m}$ and $203 \mathrm{~kW}$ for the seiners (Ministry of Environment and Food of Denmark, Danish Agrifish Agency), and were fishing with the most commonly used gears, including ground rope and

\subsection{Sampling and assessment onboard the fishing vessels}

Fishing was conducted for a total of eight days distributed on three fishing trips per vessel between 17 August and 10 October 2017 in (Fig. 1). This had two advantages: more data could be collected as capacity during transportation (maximum 80 individuals per vessel) and holding on land (maximum 320 individuals) was limited; and it allowed accounting for a naturally high variability in survival probabilities within the season. Onboard the trawler, each fishing trip lasted for two days and samples were collected from two hauls per day. Onboard the Danish seiner, each fishing trip lasted for two or three days, as additional hauls were required to obtain enough plaice below $27 \mathrm{~cm}$ (Fig. 1). The sampling protocol was consistent for both vessels. Two researchers had been trained together prior to the trials to harmonize the onboard assessments. Each researcher was on the same vessel throughout the experiment.

Operational (date, start time, time when codend reached the sea surface, time when codend was hauled onboard the vessel, GPS position of the haul) and environmental conditions (depth, air temperature, water temperatures at the sea bottom and sea surface, cloud cover, wind force, wind direction, sea state) were recorded for each haul. For the trawler, air temperature was measured under 
the covered deck to account for the protection of the catch against direct sunlight ("Handy Polaris 2",

109 Oxyguard, Denmark), contrary to the seiner for which the catch was on open deck and air temperature 110 given by the local weather supplier (Danish Meteorological Institute, Denmark). Fishing depth and water temperatures were recorded during the hauls with two "DST CTD" loggers (Star-Oddi, Iceland) mounted on the headline and footrope of the gears. Wind force and direction were given by the local weather supplier. Cloud cover (\%) and sea state were visually estimated, the latter on a scale from 1 to $4[24]$.

The catch was sorted by the fishermen according to their normal practice. Onboard the trawler, catches from both codends were emptied in a container called the fish hopper (about $2 \mathrm{~m}$ fall) before being sorted on a conveyor belt and put into baskets for subsequent gutting. Discards were returned to the sea by the conveyor belt throughout the sorting process. Onboard the seiner, the codend was also emptied in a fish hopper (about $1 \mathrm{~m}$ fall), but fish were sorted on a sorting table directly connected to the hopper. Fish were put in compartments beneath the sorting table for subsequent gutting. Discards were directly transferred back to the sea using a simple ramp system. For each gear, six plaice $<27 \mathrm{~cm}$ were, instead of being discarded, sampled for assessment at five evenly distributed sampling points from the beginning to the end of the sorting process for a total of 30 experimental fish sampled per haul. To identify the sampling interval for each haul, the total duration of the sorting process estimated by the fishers was divided by four (the first sample was taken in the beginning of the sorting). The six fish sampled per sampling point were then transferred to a 10-1 container awaiting assessment. After noting down the time when starting the assessment, each fish was transferred to an assessment container (40 $\mathrm{cm} \times 60 \mathrm{~cm} \times 20 \mathrm{~cm}$ ) filled with seawater, where its vitality class was assigned according to Table 1 [25]. The air exposure time experienced by each fish was the difference between the time of assessment start and the time when the catch was hauled onboard the vessel. Total length ( $\mathrm{cm}$ below) was measured before each fish had a Passive Integrated Transponder (PIT) tag (“HPT 12”, Biomark, USA) implanted subcutaneously on the pigmented side just behind the head for identification. The tag was inserted using an implant gun for good syringe control. Special attention was given to minimize the puncture hole and the needle penetration depth. The assessment lasted for less than one minute. Subsequently, the fish was stored in a 10-1 container filled with water until all six individuals were assessed. 
In the fish hold of the vessel, each of the six fish was transferred into a random drawer of one

137 of two survival units (SU, Fig. 2A). The SUs were designed specifically for this experiment and 138 consisted of eight drawers, each with a volume of $241(40 \mathrm{~cm}$ x $60 \mathrm{~cm}$ x $11 \mathrm{~cm})$ (Maaskant Shipyards 139 Stellendam, Netherlands) and was holding up to five plaice. The flow of surface sea water to each SU 140 was above $12 \mathrm{l} / \mathrm{min}$ [19]. The water flow was monitored 4-5 times per day together with oxygen 141 saturation and water temperature ("Handy Polaris 2", Oxyguard, Denmark), and salinity (refractometer, 142 Akudim, Denmark).

143 In the harbor basin, the water supply was disconnected from the SUs to prevent the supplied 144 water from potentially reducing in quality. The SUs were unloaded from the vessel and transported 1.6 $145 \mathrm{~km}$ to the facilities where oxygen saturation was inspected on arrival. The time from closing water 146 supply until transferring the fish into the observation tanks varied, but was usually about 15 min and 147 never exceeded $45 \mathrm{~min}$. Transfer from the fishing operations to the holding tanks can induce additional stress, e.g. by the movements of the vessel and truck. This could partly be relieved by a sealed design and securely fastening the tanks to minimize water motion.

\subsection{Controls}

The ICES guidelines advice for a careful use of appropriate controls [26]. Three types of control groups were used to control for different steps of the process. Control Group (CG) "land" was caught prior to the experiment by the research vessel "Havfisken" (DTU Aqua, Denmark) using a bottom otter trawl with 420 meshes (nominal mesh size: $120 \mathrm{~mm}$ ) around the fishing circle and a $90 \mathrm{~mm}$ diamond mesh codend made of $4 \mathrm{~mm}$ double twine PE knotted netting. Haul duration was $15 \mathrm{~min}$ and plaice $<27$ $\mathrm{cm}$ were randomly picked from the catch. The fish were stored inside SUs that were transported $0.9 \mathrm{~km}$ to the laboratory. The fish were transferred into independent flow-through acclimation tanks $(2 \mathrm{~m} \times 2$ $\mathrm{m} \times 0.5 \mathrm{~m}$ ) filled with 14001 of seawater (water flow per tank: $10 \mathrm{l} / \mathrm{min}$ ). Water temperature, dissolved oxygen and salinity were monitored and dead individuals removed following the same protocols as described below for the experimental tanks. During acclimation, the fish were fed with deep water shrimps (Pandalus borealis) ad libitum. After minimum seven days, 16 randomly selected fish, CG 
"land", were transferred to the observation tanks (one fish per tank) together with the experimental fish to control for the holding conditions.

For CG "acclim.", 20 of the acclimated fish were randomly picked from the acclimation tank and distributed equally in four SUs on each experimental day (two units for each vessel). After being transported from the laboratory to the fishing ground, these control fish were treated like experimental fish, i.e., assessed, tagged, and transported in the SUs to the laboratory. Thus, CG "acclim." controlled for the assessment, tagging, transportation and holding conditions in the laboratory.

Ten fish $<$ MCRS constituting CG "trawl" were caught by the commercial trawler on each experimental day during short hauls of $15 \mathrm{~min}$. These randomly picked fish were assessed, tagged and randomly transferred into a SU like the experimental fish. Thus, they entered the experiment without a previous acclimation period and controlled for the assessment, tagging, transportation, and holding conditions.

\subsection{Monitoring at the holding facility on land}

Upon arrival to the land-based facility, both control and experimental individuals were randomly assigned one of the sixteen observation tanks ( $1 \mathrm{~m} \times 1 \mathrm{~m} \times 0.5 \mathrm{~m}$; max. 20 fish per tank) filled with 3001 of seawater (Fig. 2B). This strategy enabled us to control for potential tank effects, i.e., any differences between tanks that were independent of treatment effects. The tanks were part of a semirecirculated system without biofilter. The hourly turnover rate was $\sim 2001 / \mathrm{min}$ of which addition of new water to the system was $\sim 12$ 1/min. Each tank contained an air stone to keep oxygen levels high. A sand layer of $2 \mathrm{~cm}$ covered the bottom of each tank. The ambient light-dark ratio was kept constant at 8 hours light (08:00-16:00) and 16 hours dark (16:00-08:00), however, light was switched on during assessments in the evening $(\sim 1 \mathrm{~h})$. All observation tanks were covered with polystyrene plates $(2.5 \mathrm{~cm}$ thick) to avoid direct illumination and reduce stress in the fish.

After the first monitoring upon arrival, fish mortality, dissolved oxygen and water temperature were monitored three times a day $(08: 00,14: 00,20: 00)$ during the first week. The second week, fish were monitored twice per day $(08: 00,20: 00)$ and fed deep sea shrimps ad libitum. Feeding took place before the lights were switched off (16:00) as plaice are known to feed and be more active at dusk and 
during night $[27,28]$. Excretions and food remains were removed during the evening assessment to

190 prevent degraded shrimps from influencing the water quality. Salinity was recorded daily, and ammonia

191 levels in the individual observation tanks were analyzed weekly ("VISOCOLOR ECO Ammonium 3",

192 Aquacultur, Germany). The monitoring period was set to two weeks to observe all delayed mortalities resulting from capture and handling, but not adding additional stress $[18,19,29]$.

All experiments were performed in accordance with the European and Danish legislation on animal experimentation and following the guidelines pointed out in of the International Council for the Exploration of the Sea (ICES) Working Group on Methods for Estimating Discard Survival 197 (WGMEDS) [26].

\subsection{Data analysis}

For each gear, haul duration, catch weight, fishing depth, water temperature at the bottom and at the surface, air temperature, cloud cover, sea state, wind force, wind direction, catch composition, air exposure and fish length were recorded or collected from a third-party. Data exploration (e.g. outliers, collinearity, relationships and interactions between variables) followed the protocol described in [30]. Non-parametric Kaplan-Meier survival curves are functions of the observed data. They gave the proportion of sampled individuals alive at each time point during captivity. Time zero was defined to be the moment when the fish were transferred into the tanks at the holding facility $[27,28]$. Although this means that the time between being caught and time zero was longer for fish from earlier hauls during a day, it represents the moment, when conditions became the same for all individuals from one day and no further interactions like transportation or transfer were needed. Fish that died during the transportation process were treated as being dead at time zero.

High correlation was found between haul duration, catch weight and air exposure, and between

211 fishing depth and bottom sea temperature, and so haul duration, catch weight and fishing depth were 212 excluded from further analyses. Data exploration indicated a potential effect of air exposure, air and 213 bottom temperatures. All were treated as continuous except for air exposure in the case of the seiner for which data exploration indicated a possible effect when treated as a categorical covariate with two 215 levels, i.e., less and more than 30 minutes. The threshold of 30 min was chosen to best fit the observed 
data as plotted using the Kaplan-Meier survival curves. Indeed, there seemed to be different

217 mechanisms at stake when caught by the two vessels. Previous studies have shown an additional effect

218 of fish length on survival probability, which was therefore also tested. For both gears, continuous explanatory variables ranged across different scales (Table 2), and were therefore centered and standardized.

Our data analysis followed closely [11]. A parametric Weibull mixture distribution model was used to model discard survival, with $\pi$ the probability that a fish died after capture, handling and distribution $[14,31,32]$.

The chosen explanatory variables air exposure, fish length, and air and bottom temperatures were tested as covariates on the three parameters describing the survival model, i.e., $\alpha, \gamma$ and $\pi$ [11]. This resulted in a total of 4096 potential models. Model parameters were estimated by a maximization of the model likelihood using a quasi-Newton optimization algorithm [33].

Model selection was run for each gear separately. An information-theoretic approach was used to identify which of the covariates were important determinants of survival probability $[34,35]$. Among all models with a relative difference in AIC to the model having the lowest AIC less than two, the simpler model with highest weight was selected as the best model. Model fit was assessed visually by superimposing the predicted survival curves on the Kaplan-Meier survival curves [9,14].

Confidence intervals of the survival rates were estimated by a parametric bootstrap based on Monte Carlo simulation with 5000 iterations, with the regression parameters simulated according to a multivariate Gaussian distribution at each iteration $[14,31,32]$. Uncertainty due to the selection of hauls was estimated by randomly re-sampling $m$ hauls with replacement from the $m$ observed hauls. The covariates in the chosen best models did not depend on the sampled fish, but on the haul selection only. Therefore, the observed fish were not re-sampled to capture the variability due to the selection of fish in each haul. The overall survival rate for each gear was given as the median, and its $95 \%$-confidence interval $(\mathrm{CI})$ as the range between the $5^{\text {th }}$ and the $95^{\text {th }}$ centile.

Overall survival rates for each gear are dependent on the number of observed fish for each level 243 of the selected covariates. Thus, survival rates were also predicted independently for given values of 
244 the selected covariates within the ranges of the experimental data, i.e., air exposure from 0 min to 62 min for the trawler, and air exposure below and above 30 minutes and bottom temperatures of $10^{\circ} \mathrm{C}$ and

$24617^{\circ} \mathrm{C}$ for the seiner. Survival was estimated at the asymptote, i.e., calculated as $1-\pi$. Confidence

247 intervals of the survival rates were estimated as previously, but accounted only for the variation of the

\section{Results}

\subsection{Overview of hauls, catches and experimental conditions}

In total, 12 experimental (333 fish sampled) and six control hauls (60 fish sampled) were conducted by the trawler, and 16 experimental hauls by the seiner (281 fish sampled; Table 2 and 3 ). Average haul duration for experimental hauls was shorter and catch weights larger for the trawler than for the seiner. The range of the fishing depth was similar. Air temperature values measured under the covered deck for the trawler were similar to the values on deck for the seiner.

Average time fish spent in air, i.e., the sum of air exposure for each fish divided by the number of sampled fish, was similar for both vessels (18 $\mathrm{min}$ and $15 \mathrm{~min}$ for the trawler and seiner, respectively), but maximum air exposure was longer for fish onboard the trawler (62 min and $45 \mathrm{~min}$ for the trawler and seiner, respectively).

The operational factors were representative of commercial practices in Danish waters. The sampled individuals were below the MCRS for plaice $(27 \mathrm{~cm})$ except for three individuals $(28 \mathrm{~cm})$ caught by the seiner (Fig. 3, Table 2). For the Danish seiner, all captured individuals below MCRS were sampled. For the trawler, an additional haul allowed to measure all plaice below MCRS caught so that

269 difference in the mesh sizes used, i.e., $90 \mathrm{~mm}$ for the trawler and $120 \mathrm{~mm}$ for the seiner. 

both gears. There was a higher proportion of lively fish (vitality class 1) for the seiner and moribund

fish (vitality class 4) for the trawler (Table 4). For a given vitality class, fish caught by the trawler generally showed more damage than fish caught by the seiner. For fish caught by the seiner, impairment of body movements were recorded more often than damage.

Oxygen levels in the SUs were above 50\% saturation when arriving to the land-based facilities.

279

280

281

\subsection{Discard survival estimates and factors influencing survival}

The mortality of the experimental fish from the trawler was highest in the first week, but stabilized during the second week (Fig. 4). An asymptote was reached for both gears (Fig. 4). Few models, including all of the four tested parameters (Table 4) in different combinations, had good support in the data, i.e., a relative difference in AIC less than two for both gears ( 5 models out of 4096 for both gears, Table 6). Good correspondence of the predicted survival function with the Kaplan-Meier survival curve for the trawler indicated a good fit of the final model (Fig. 4). The observed Kaplan-Meier survival curve for the seiner was slightly above the predicted survival function, but still within the estimated 95\%-confidence interval (Fig. 4).

The best survival model for the trawler included the effect of air exposure on $\pi$ (Table 6). Indeed, air exposure was present only among the best models, whereas fish size and air and bottom temperatures had a limited importance as an explanatory variable for survival onboard the trawler (relative importance less than 0.7 , Table 5).

The best survival model for the seiner included the effect of air exposure, and air and bottom temperatures on $\alpha$ as well as the effect of air exposure and bottom temperature on $\pi$ (Table 6). All three covariates were present among the best models (relative importance more than 0.7 , Table 5). However, a simpler model including only the effect of air exposure and air temperature on $\alpha$, and the effect of air exposure and bottom temperature on $\pi$ showed similar support in the data, and was thereafter chosen as 
the best model (Table 6). The effects of the explanatory variables were at the same order of magnitude, but the effect of air exposure on $\alpha$ was 3 and 7 times larger than those of air temperature and bottom temperature, respectively (Table 7).

The shape parameter $\gamma$ was systematically equal to 1 for both gears (Tables 6 and 7), which means that the estimated survival function follows an exponential distribution, i.e., the probability of an individual dying at time $\mathrm{t}+\mathrm{dt}$ conditional on it being alive at time $\mathrm{t}$ is constant on the explanatory variables.

The estimated values for the parameter $\pi$ differed between vessels, resulting in an overall higher survival of plaice from the seiner (78\%, CI: 67-87) than the trawler (44\%, CI: 37-52) (Table 8, Fig. 4). Air exposure had a negative effect on survival for both vessels, i.e., survival probability decreased when air exposure increased (Table 7, Fig. 4). Bottom temperature had a negative effect on survival for the seiner, i.e., survival probability decreased with increasing bottom temperatures (Table 7, Fig. 5).

Looking at the covariate effects independently of the number of experimental fish sampled at each covariate level, fish caught by the trawler had a survival probability of $62 \%$ (CI: 24-89) if released immediately, but this decreased to 8\% (CI: 2-31) after 60 min of air exposure (Fig. 5). Survival of fish released before 30 minutes from the seiner was estimated to $86 \%$ (CI: 46-97), with higher survival at bottom temperatures of $10^{\circ} \mathrm{C}(91 \%$, CI: $66-98)$ than $17^{\circ} \mathrm{C}(77 \%$, CI: 38-94). The survival decreased to $20 \%$ (CI: 4-62) if released after 30 minutes on deck, again with higher survival at bottom temperature of $10^{\circ} \mathrm{C}(31 \%$, CI: $8-70)$ than $17^{\circ} \mathrm{C}(12 \%$, CI: 3-42) (Fig. 5). Survival of control fish was high (range: $84-100 \%$, Table 8$)$.

\section{Discussion}

\subsection{Discard survival in summer}

The survival of plaice from the trawler was similar to the 39 and $42 \%$ found for plaice discarded from otter trawlers in the same season in the Skagerrak [15] and the North Sea [12], respectively. However, it was lower than the $76 \%$ and $75 \%$ found in winter in Skagerrak for small-scale trawlers and average sized trawlers, respectively $[13,43]$. Lower survival rates in summer fit well with findings of 
previous studies, where mild compared to cold conditions and temperature shock between colder bottom

324 sea water and warmer air have previously been identified to increase stress and thus discard mortality in fish $[19,44,45]$.

326

327

328

329

330

331

\subsection{Gear and covariate effects on discard survival}

The Kaplan-Meier survival curve for the seiner was slightly above the predicted survival function. An effect of air exposure was found both on the survival function $(\alpha)$, and the mixture proportion $(\pi)$, with a larger effect on the survival function. As the original sampled data included few hauls with long air exposure, fish with air exposures of more than 30 min were not as well represented as in the randomized experimental data accounting for haul uncertainty. This could explain why the Kaplan-Meier survival curve for the seiner was slightly above that of the predicted survival function.

In line with previous studies, air exposure on deck, leading to desiccation and hypoxia, was identified as the main stressor affecting plaice discard survival for both gears (e.g. $[9,13,14])$. Even though plaice have the ability to breathe via their skin, little of the oxygen taken up this way is used for respiration $[46,47]$. Air exposures longer than 30 minutes reduced survivability of fish caught by the seiner substantially, resulting in survival estimates similar to those of fish caught by the trawler. The threshold of 30 min was the most appropriate to fit the observed data.

Air exposure was identified to be an important determinant of discard survival for both fishing gears. For fish discarded from the seiner, bottom temperature was identified to have an effect on survivability as well. Reduced survival when water temperature was higher (sea bottom temperature: $\left.10-17^{\circ} \mathrm{C}\right)$ was in line with previous studies on plaice (e.g. $\left.[14,19,48]\right)$. Such an effect was not observed for the trawl-caught fish, possibly because air exposure had a stronger effect than bottom temperature compared to the seiner, or because other factors not included in the analysis, such as catch damage, were more important. Indeed, mechanical injuries such as scale loss and puncture wounds are likely to cause osmoregulatory challenges for the fish, and therefore additional stress and a reduced chance to survive the process of being discarded [20]. 
The effect of depth was confounded with that of bottom temperature. Plaice lack a swim

349

350

351

352

353

354

355

356

357

358

359

360

361

362

363

364

365

366

367

368

369

370

371

372

373

374

bladder, but other barotrauma like gas embolisms in organs or clotting of fine blood vessels cannot be excluded $[13,19,20]$.

No effect of fish length was observed, which is in line with previous results from [19] on a similar size range (average fish length of $22.2 \mathrm{~cm}$, similar to $23 \mathrm{~cm}$ for the trawler and $25 \mathrm{~cm}$ for the seiner in the present study, with most fish just below MCRS). However, when larger length ranges (23$62 \mathrm{~cm}$ total length) have been studied, higher mortalities of smaller fish have been observed relative to larger fish (e.g. [49]).

The catch was mainly composed of flatfish, as is usually the case in the Danish mixed demersal fishery during daytime in the summer season. However, it has been observed that a change in catch composition can affect discard survival rates of plaice in this fishery. For example, discard survival can be significantly higher in hauls with fewer Norway lobster, i.e., when targeting plaice, than when targeting Norway lobster (73\% and 40\% in the winter, respectively) [43]. In addition, hauls with lower amount of sediment and debris can give lower discard mortality in the small-scale fishery [15].

\subsection{Sources of uncertainty}

Captivity studies are considered to overestimate discard survivability because the fish do not experience the recovery phase in their natural habitat, but under laboratory conditions. For example, post-release predation, e.g. by sea birds [50], whose effects remain unknown [51], is not accounted for. This means that survival estimates are likely to be overestimated. On the other hand, handling related to studying survival, like assessment, tagging, transportation and transfer to SUs or observation tanks can increase stress and mortality of the fish, resulting in an underestimation of survival rates. To which extent the exclusion of predation and the addition of handling stress offset each other is undetermined. However, the effect of additional handling and holding of the fish was investigated using three types of control groups in the current study. The $100 \%$ observed survivability of CG "land" indicated optimal holding conditions. Survival estimates of fish from CG "trawl" and CG "acclim." were similar and less than $100 \%$, suggesting that transportation and/or assessment and tagging increased fish mortality. Adverse physiological reactions have not been observed for small subcutaneous tag implants in flatfish, 
although increased scar tissue deposition around the implantation site may be possible [52]. This was

376 not observed in the current study. Furthermore, a similar study added a fourth control group so that

377 acclimated controls transferred directly to the observation tanks and acclimated controls assessed and tagged before transferred to the observation tanks could be compared, and similar survival rates (94$100 \%, 16$ individuals per control group) were observed [43]. As the assessment was fast and minimally invasive, transportation was a more likely candidate for the negative effect on the survival of control fish. To properly disentangle the effects of transportation and fish assessment, future studies should follow the strategy of an additional control group that undergoes the assessment and tagging procedure, but not the transportation. The similar survival rates of CG "acclim." and CG "trawl" further suggested that the mortality generated by an additional transportation process (CG "acclim.") is similar to being caught by a short trawl haul (haul duration: $15 \mathrm{~min}$ ) (CG "trawl"). Because control specimens were generally fit as they did not go through the commercial catch and discard process, but were rather sampled by short haul duration with or without acclimatization depending on the control group, experimental mortality could have been higher than indicated by the control individuals.

Besides the experimental design, observer-bias may add to the uncertainty. For the whole experiment, the same researcher was sampling on the same vessel. Training rather than observer experience can minimize inter-rater differences [53], and this is why both researchers harmonized their assessment prior to the trials. However, an observer bias cannot be excluded. Observers may have inconsistently scored vitality, but higher vitality scores with longer air exposure were systematically recorded for both gears.

The use of Monte Carlo simulations allowed to account for the two main sources of uncertainty, i.e., the haul selection and conditions of the captivity experiment that contributed to variation in the estimated discard survival rates [14,25]. However, the parameters used were assumed to follow particular theoretical probability distributions, for which improper characterization would affect the survival estimate and its uncertainty $[25,54]$. Besides, even though the chosen models were assumed to be true, other models could describe discard survival rates equally well. Model uncertainty, which was not taken into consideration here, would increase the uncertainty around the predicted survival rates $[25,35]$. 
Danish seiners in Skagerrak operate in the demersal fishery year-round, but most of the catch is taken from May to October (Ministry of Environment and Food of Denmark, Danish Agrifish Agency). The majority of plaice (78\%, CI: 67-87) survived the discarding process when caught by the seiner from medio-August to primo-October when the water temperature is peaking. The bottom otter trawlers in Skagerrak operate year round in the mixed crustacean and demersal fish fishery. Less than half of the plaice (44\%, CI: $37-52$ ) survived when caught in during the warm period. Survival is affected by temperature $[14,19,48]$, and higher discard survival has been observed in the winter season [43].

Using the evaluation by Scientific, Technical and Economic Committee for Fisheries (STECF) 412 on the discard survival evidence provided by the Member States, the EU Commission decides whether 413 to grant exemption to a given fishery or not. The level at which survival is considered 'high' has not been defined, but is used subjectively and involves trade-offs between different management and societal objectives, driven by the management priority for that fishery at that particular time [55]. The empirical estimates of discard survival for the species caught in specific fisheries and areas for which an exemption has been granted so far range from 46 to $90 \%$ survival [55]. The present study supported the exemption granted for plaice caught with Danish seines in Union waters of ICES division 3a (Skagerrak and Kattegat) and subarea 4 (North Sea) [56].

The minimum legal mesh size for the mixed demersal fishery in the Skagerrak is $90 \mathrm{~mm}$, which is why a $90 \mathrm{~mm}$ diamond codend was used for the trawler in this study. However, this mixed demersal fishery may target either plaice or Norway lobster depending on the season and choice of fishing ground. A $120 \mathrm{~mm}$ diamond codend is commonly used when targeting plaice, but this is not the case for all vessels. A larger mesh size in the codend has been found to improve health scores for trawl-caught skates together with improving size selectivity [57], and it is therefore expected that discard survival of plaice could be higher in the $120 \mathrm{~mm}$ than the $90 \mathrm{~mm}$ diamond mesh codend. Thus, our observed discard survival rate stands as a "worst-case scenario" at the fishery level. Other trawl modifications improving size selectivity can also improve discard survival as seen for a double codend tested for prawns [58]. In the Danish trawl fishery for plaice and Norway lobster, a horizontally divided codend seems promising for its ability to separate different species and thus reduce fish damage by limiting friction from species 
431 with hard and spiny body surfaces [59]. Furthermore, handling procedures can be improved to increase

433 sorted, or using a discarding chute system for Norway lobster [60].Vitality classes were here described to better assess fish condition in relation to their survival. Using vitality classes as a proxy for discard survival has been suggested, e.g. [61], and specifically tested for otter trawl-caught plaice [13,14]. Assessing vitality is easy and could be a cost-efficient method to obtain survival probabilities from a range of vessels and operational conditions in a fishery, e.g. through self-sampling programs, and should be further explored for the Danish mixed fisheries.

This study compared discard survival between a bottom otter trawler and a Danish seiner operating under similar conditions in Skagerrak, and found average survival estimates to be lower for plaice caught by the trawler than the seiner under the environmental conditions from which fish was assessed. Air exposure was the most important factor in determining survivability of fish from the trawler. For the seiner, bottom temperature was an additional important determinant. Thus, the environmental conditions affected the survival in the two fisheries differently. Air exposure affected survival relatively less when fishing with the seiner than the trawler as the fish was caught at the end of the fishing process and are less exhausted and damaged, and so the effect of bottom temperature became relatively more important.

\section{Acknowledgements}

The authors thank the very helpful crews of both vessels S84 Ida-Katrine and S15 Vera-Marie, and Henrik Lund from the Danish Fishermen Producer Organisation. Furthermore, we would like to thank the technicians from DTU-Aqua (Helle Andersen, Reinhardt Jensen, Brian Thomsen, Per Christensen, Søren Eskildsen, Søren Grønby), the crew of Havfisken, Peter Skov and Carlos LetelierGordo, as well as Kasparas Bagdonas, for their involvement in the project, i.e., designing and setting up the facilities, sampling control fish, providing essential support during the fishing trips or assessing the fish during the monitoring period. We are also very grateful to ICES-WGMEDS for guidelines and discussions on how to best run discard survival studies and analyze survival data. This work was 
457 supported by the Ministry of Environment and Food of Denmark and EU through the European 458 Maritime and Fisheries Fund (EMFF) under the project COPE (grant no. 33113-B-16-086). 
[1] M.W. Davis, Key principles for understanding fish bycatch discard mortality, Can. J. Fish. Aquat. Sci. 59 (2002) 1834-1843. doi:10.1139/f02-139.

[2] M.K. Broadhurst, P. Suuronen, A. Hulme, Estimating collateral mortality from towed fishing gear, Fish Fish. 7 (2006) 180-218. doi:10.1111/j.1467-2979.2006.00213.x.

[3] S.S. Uhlmann, M.K. Broadhurst, Mitigating unaccounted fishing mortality from gillnets and traps, Fish Fish. 16 (2013) 183-229. doi:10.1111/faf.12049.

[4] L. Borges, E. Penas Lado, Discards in the Common Fisheries Policy: The Evolution of the Policy, in: Eur. Land. Oblig., Springer International Publishing, Cham, 2019: pp. 27-47. doi:10.1007/978-3-030-03308-8_2.

[5] Regulation (EU) No 1380/2013 of the European Parliament and of the Council of 11 December 2013 on the Common Fisheries Policy, 2013. http://eur-lex.europa.eu/legalcontent/EN/TXT/?uri=uriserv:OJ.L .2013.354.01.0022.01.ENG.

[6] Regulation (EU) No 2016/72 of the European Parliament and of the Council of 22 January 2016 on the Common Fisheries Policy, 2016. http://data.europa.eu/eli/reg/2016/72/oj.

[7] L. van Hoof, M. Kraan, N.M. Visser, E. Avoyan, J. Batsleer, B. Trapman, Muddying the Waters of the Landing Obligation: How Multi-level Governance Structures Can Obscure Policy Implementation, in: Eur. Land. Oblig., Springer International Publishing, Cham, 2019: pp. 179-196. doi:10.1007/978-3-030-03308-8_9.

[8] F. Sardà, M. Coll, J.J. Heymans, K.I. Stergiou, Overlooked impacts and challenges of the new European discard ban, Fish Fish. 16 (2015) 175-180. doi:10.1111/faf.12060.

[9] M. Morfin, S. Méhault, H.P. Benoît, D. Kopp, Narrowing down the number of species requiring detailed study as candidates for the EU Common Fisheries Policy discard ban, Mar. Policy. 77 (2017) 23-29. doi:10.1016/j.marpol.2016.12.003.

[10] T. Noack, R.P. Frandsen, K. Wieland, L.A. Krag, F. Berg, N. Madsen, Fishing profiles of Danish seiners and bottom trawlers in relation to current EU management regulations, Fish. Manag. Ecol. 24 (2017) 436-445. doi:10.1111/fme.12244.

[11] J. Depestele, M. Desender, H.P. Benoît, H. Polet, M. Vincx, Short-term survival of discarded target fish and non-target invertebrate species in the "eurocutter" beam trawl fishery of the southern North Sea, Fish. Res. 154 (2014) 82-92. doi:10.1016/j.fishres.2014.01.018.

[12] T. Catchpole, P. Randall, R. Forster, S. Smith, A.R. Santos, F. Armstrong, S. Hetherington, V. Bendall, D. Maxwell, Estimating the discard survival rates of selected commercial fish species (plaice - Pleuronectes platessa) in four English fisheries (MF1234), 2015.

[13] C. Methling, P. V. Skov, N. Madsen, Reflex impairment, physiological stress, and discard mortality of European plaice pleuronectes platessa in an otter trawl fishery, ICES J. Mar. Sci. 74 (2017) 1660-1667. doi:10.1093/icesjms/fsx004.

[14] M. Morfin, D. Kopp, H.P. Benoît, S. Méhault, P. Randall, R. Foster, T. Catchpole, Survival of European plaice discarded from coastal otter trawl fisheries in the English Channel, J. Environ. Manage. 204 (2017) 404-412. doi:10.1016/j.jenvman.2017.08.046.

[15] M. Eskelund, C. Methling, P. Vilhelm Skov, N. Madsen, Survival of discarded plaice ( Pleuronectes platessa ) from Norway lobster ( Nephrops norvegicus ) otter-trawl fishery, J. Appl. Ichthyol. 35 (2019) 645-654. doi:10.1111/jai.13888.

[16] S.B.M. Kraak, U. Fröse, A. Velasco, U. Krumme, Prediction of delayed mortality using vitality scores and reflexes, as well as catch, processing, and post-release conditions: evidence from discarded flatfish in the Western Baltic trawl fishery, ICES J. Mar. Sci. 76 (2018) 330341. doi:10.1093/icesjms/fsy129.

[17] B. van Marlen, P. Molenaar, K.J. van der Reijden, P.C. Goudswaard, R.A. Bol, S.T. Glorius, R. Theunynck, S.S. Uhlmann, Overleving van discard platvis - Vaststellen en verhogen (C180/15), 2016.

[18] S.S. Uhlmann, R. Theunynck, B. Ampe, M. Desender, M. Soetaert, J. Depestele, Injury, reflex impairment, and survival of beam-trawled flatfish, ICES J. Mar. Sci. 73 (2016) 578-589. doi:10.1093/icesjms/fst048.

[19] K.J. van der Reijden, P. Molenaar, C. Chen, S.S. Uhlmann, P.C. Goudswaard, B. van Marlen, Survival of undersized plaice (Pleuronectes platessa), sole (Solea solea), and dab (Limanda 
limanda) in North Sea pulse-trawl fisheries, ICES J. Mar. Sci. 74 (2017) 1672-1680. doi:10.1093/icesjms/fsx019.

[20] H.P. Benoît, S. Plante, M. Kroiz, T. Hurlbut, A comparative analysis of marine fish species susceptibilities to discard mortality: effects of environmental factors, individual traits, and phylogeny, ICES J. Mar. Sci. 70 (2013) 99-113. doi:10.1093/icesjms/fss132.

[21] T. Noack, D. Stepputtis, N. Madsen, K. Wieland, S. Haase, L.A. Krag, Gear performance and catch process of a commercial Danish anchor seine, Fish. Res. 211 (2019) 204-211. doi:10.1016/j.fishres.2018.11.012.

[22] R. Ljøen, A. Svansson, Long-term variations of subsurface temperatures in the Skagerrak, Deep Sea Res. Oceanogr. Abstr. 19 (1972) 277-288. doi:10.1016/0011-7471(72)90021-6.

[23] EU, COUNCIL REGULATION (EC) No 850/98 of 30 March 1998 for the conservation of fishery resources through technical measures for the protection of juveniles of marine organisms, Off. J. Eur. Communities. L125 (1998) 1-15.

[24] D.A. Wileman, R.S.T. Ferro, R. Fonteyne, R.B. Millar, Manual of methods of measuring the selectivity of towed fishing gears, ICES Coop. Res. Rep. (1996) 1-126.

$\mathrm{http}$ ://www.eurobis.org/imis?module=ref\&refid=242792\&printversion=1\&dropIMIStitle=1.

[25] H.P. Benoît, T. Hurlbut, J. Chassé, Assessing the factors influencing discard mortality of demersal fishes using a semi-quantitative indicator of survival potential, Fish. Res. 106 (2010) 436-447. doi:10.1016/j.fishres.2010.09.018.

[26] ICES, Report of the Workshop on Methods for Estimating Discard Survival (WKMEDS), 1721 February 2014, Copenhagen, Denmark, 2014. http://www.ices.dk/sites/pub/Publication Reports/Expert Group Report/acom/2014/WKMEDS/01 WKMEDS - Report of the Workshop on Methods for Estimating Discard Survival.pdf\#search=WKMEDS.

[27] G. Hempel, Diurnal Variations in Catch, Activity and Feeding of Plaice in the German Bight. Rapp. P.-v. Réun. Cons. perm. int. Explor. Mer, 155, 1964.

[28] M.T. Burrows, Foraging time strategy of small juvenile plaice: A laboratory study of diel and tidal behaviour patterns with Artemia prey and shrimp predators, Mar. Ecol. Prog. Ser. 115 (1994) 31-40.

[29] N. Yochum, C.S. Rose, C.F. Hammond, Evaluating the flexibility of a reflex action mortality predictor to determine bycatch mortality rates: A case study of Tanner crab (Chionoecetes bairdi) bycaught in Alaska bottom trawls, Fish. Res. 161 (2015) 226-234. doi:10.1016/j.fishres.2014.07.012.

[30] A.F. Zuur, E.N. Ieno, C.S. Elphick, A protocol for data exploration to avoid common statistical problems, Methods Ecol. Evol. 1 (2009) 3-14. doi:10.1111/j.2041210x.2009.00001.x.

[31] H.P. Benoît, T. Hurlbut, J. Chassé, I.D. Jonsen, Estimating fishery-scale rates of discard mortality using conditional reasoning, Fish. Res. 125-126 (2012) 318-330. doi:10.1016/j.fishres.2011.12.004.

[32] H.P. Benoît, C.W. Capizzano, R.J. Knotek, D.B. Rudders, J.A. Sulikowski, M.J. Dean, W. Hoffman, D.R. Zemeckis, J.W. Mandelman, A generalized model for longitudinal short- and long-term mortality data for commercial fishery discards and recreational fishery catch-andreleases, ICES J. Mar. Sci. 72 (2015) 997-1021. doi:10.1093/icesjms/fsv039.

[33] R.H. Byrd, P. Lu, J. Nocedal, C. Zhu, A Limited Memory Algorithm for Bound Constrained Optimization, SIAM J. Sci. Comput. 16 (1995) 1190-1208. doi:10.1137/0916069.

[34] H. Akaike, Likelihood of a model and information criteria, J. Econom. 16 (1981) 3-14. doi:10.1016/0304-4076(81)90071-3.

[35] K. Burnham, D.R. Anderson, Model Selection and Multimodel Inference : a practical information-theoretic approach, 2nd ed. Co, Springer New York, New York, NY, 2004. doi:10.1007/b97636.

[36] R.C. Team, R: A Language and Environment for Statistical Computing, (2017). https://www.rproject.org/.

[37] A.C. Davison, D. V. Hinkley, Bootstrap methods and their application, Cambridge University Press., 1997. https://findit.dtu.dk/en/catalog/2304969268 (accessed February 20, 2019).

[38] A. Canty, B. Ripley, boot: Bootstrap R (S-Plus) functions, (2017).

[39] H. Wickham, R. Francois, H. Henry, K. Müller, dplyr: A Grammar of Data Manipulation, 
(2017). https://cran.r-project.org/package=dplyr.

[40] H. Wickham, Ggplot2 : elegant graphics for data analysis, Springer, 2009.

[41] T. Therneau, A Package for Survival Analysis in S, (2015). https://cran.rproject.org/package= $=$ survival.

[42] T.M. Therneau, P.M. Grambsch, Modeling Survival Data: Extending the Cox Model, Springer New York, New York, NY, 2000. doi:10.1007/978-1-4757-3294-8.

[43] E. Savina, T. Noack, J.D. Karlsen, Effects of season, target species and codend design on the survival of undersized plaice (Pleuronectes platessa) discarded in the bottom otter trawl mixed fisheries in Skagerrak, Fish. Res. 219 (2019) 105311. doi:10.1016/j.fishres.2019.105311.

[44] B.J. Galloway, J.D. Kieffer, The Effects of an Acute Temperature Change on the Metabolic Recovery from Exhaustive Exercise in Juvenile Atlantic Salmon ( Salmo salar ), Physiol. Biochem. Zool. 76 (2003) 652-662. doi:10.1086/376921.

[45] F. Giomi, S. Raicevich, O. Giovanardi, F. Pranovi, P. Di Muro, M. Beltramini, Catch me in winter! Seasonal variation in air temperature severely enhances physiological stress and mortality of species subjected to sorting operations and discarded during annual fishing activities, Hydrobiologia. 606 (2008) 195-202. doi:10.1007/s10750-008-9336-x.

[46] J.F. Steffensen, J.P. Lomholt, Cutaneous oxygen uptake and its relation to skin blood perfusion and ambient salinity in the plaice, Pleuronectes platessa, Comp. Biochem. Physiol. 81 (1985) 373-375. doi:10.1016/0300-9629(85)90150-1.

[47] J.F. Steffensen, J.P. Lomholt, K. Johansen, The relative importance of skin oxygen uptake in the naturally buried plaice, pleuronectes platessa, exposed to graded hypoxia, Respir. Physiol. 44 (1981) 269-275. doi:10.1016/0034-5687(81)90022-0.

[48] F.A. van Beek, P.I. van Leeuwen, A.D. Rijnsdorp, On the survival of plaice and sole discards in the otter-trawl and beam-trawl fisheries in the North Sea, Netherlands J. Sea Res. 26 (1990) $151-160$.

[49] A.S. Revill, M.K. Broadhurst, R.B. Millar, Mortality of adult plaice, Pleuronectes platessa and sole, Solea solea discarded from English Channel beam trawlers, Fish. Res. 147 (2013) 320326. doi:10.1016/j.fishres.2013.07.005.

[50] S. Garthe, K.C.J. Camphuysen, R.W. Furness, Amounts of discards by commercial fisheries and their significance as food for seabirds in the North Sea, Mar. Ecol. Prog. Ser. 136 (1996) 1-11. doi:10.3354/meps 136001 .

[51] G.D. Raby, J.R. Packer, A.J. Danylchuk, S.J. Cooke, The understudied and underappreciated role of predation in the mortality of fish released from fishing gears, Fish Fish. 15 (2014) 489505. doi:10.1111/faf.12033.

[52] T. Loher, R. Rensmeyer, Physiological responses of Pacific halibut, Hippoglossus stenolepis, to intracoelomic implantation of electronic archival tags, with a review of tag implantation techniques employed in flatfishes, Rev. Fish Biol. Fish. 21 (2011) 97-115. doi:10.1007/s11160-010-9192-4.

[53] P. Meeremans, N. Yochum, M. Kochzius, B. Ampe, F.A.M. Tuyttens, S.S. Uhlmann, Interrater reliability of categorical versus continuous scoring of fish vitality: Does it affect the utility of the reflex action mortality predictor (RAMP) approach?, PLoS One. 12 (2017) 1-22. doi:10.1371/journal.pone.0179092.

[54] A.M. Law, W.D. Kelton, Simulation modeling and analysis, McGraw-Hill, 1982.

[55] D. Rihan, S.S. Uhlmann, C. Ulrich, M. Breen, T. Catchpole, Requirements for Documentation, Data Collection and Scientific Evaluations, in: Eur. Land. Oblig., Springer International Publishing, Cham, 2019: pp. 49-68. doi:10.1007/978-3-030-03308-8_3.

[56] Commission delegated regulation (EU) 2018/2035 of 18 October 2018 specifying details of implementation of the landing obligation for certain demersal fisheries in the North Sea for the period 2019-2021, 2018 (2019).

[57] R. Enever, A.S. Revill, R. Caslake, A. Grant, Discard mitigation increases skate survival in the Bristol Channel, Fish. Res. 102 (2010) 9-15. doi:10.1016/j.fishres.2009.09.013.

[58] M.K. Broadhurst, R.B. Millar, S.S. Uhlmann, Using a double codend to reduce discard mortality, ICES J. Mar. Sci. 66 (2009) 2077-2081. doi:10.1093/icesjms/fsp155.

[59] J.D. Karlsen, L.A. Krag, C.M. Albertsen, R.P. Frandsen, From fishing to fish processing: Separation of fish from crustaceans in the Norway lobster-directed multispeciestrawl fishery 
improves seafood quality, PLoS One. 10 (2015) 1-20. doi:10.1371/journal.pone.0140864.

[60] L. Mérillet, S. Méhault, T. Rimaud, C. Piton, F. Morandeau, M. Morfin, D. Kopp, Survivability of discarded Norway lobster in the bottom trawl fishery of the Bay of Biscay, Fish. Res. 198 (2018) 24-30. doi:10.1016/j.fishres.2017.10.019.

[61] M.W. Davis, Fish stress and mortality can be predicted using reflex impairment, Fish Fish. 11 (2010) 1-11. doi:10.1111/j.1467-2979.2009.00331.x. 
Figure 1. Overview of the fishing grounds used by the bottom-otter trawler (lines) and the Danish seiner (rounded triangular shapes) for the three sub-cruises in Skagerrak, north of Denmark.

Figure 2. Storage of fish. A. Survival unit $(118.3 \times 78.3 \times 65.7 \mathrm{~cm})$ with 8 drawers $(60 \times 40 \times 11 \mathrm{~cm})$ used to hold fish onboard the vessel and transport fish to the holding facility. B. Holding facility consisting of 4 rows of 4 tanks ( $1 \mathrm{~m} \mathrm{x} 1 \mathrm{~m}$ ) with semi-recirculated sea water.

Figure 3. Number of fish sampled by length class for the bottom-otter trawl ('OTB') and the Danish seine ('SDN'). The dashed line indicates the Minimum Conservation Reference Size (MCRS) for plaice $(27 \mathrm{~cm})$.

Figure 4. Curves of survival functions for undersized plaice caught by the bottom otter trawler ('OTB', left) and Danish seiner ('SDN', right) from captivity data estimated using the non-parametric KaplanMeier method (black full line) and the parametric mixture Weibull method (grey full line) with 95\%confidence interval (grey dashed lines).

Figure 5. Discard survival as a function of air exposure in minutes (black) with $95 \%$-confidence upper and lower limits estimated by non-parametric bootstrap (grey) for undersized plaice caught by the bottom otter trawler ('OTB', left) and Danish seiner ('SDN', right). The model fit, and therefore the underlying mechanism at stake, showed to be different for the two gears, i.e., survival probability as a function of air exposure was best modelled as a continuous variable for the OTB and as a categorical variable with two levels for the SDN - refer to section 2.6 in the text for additional details. 


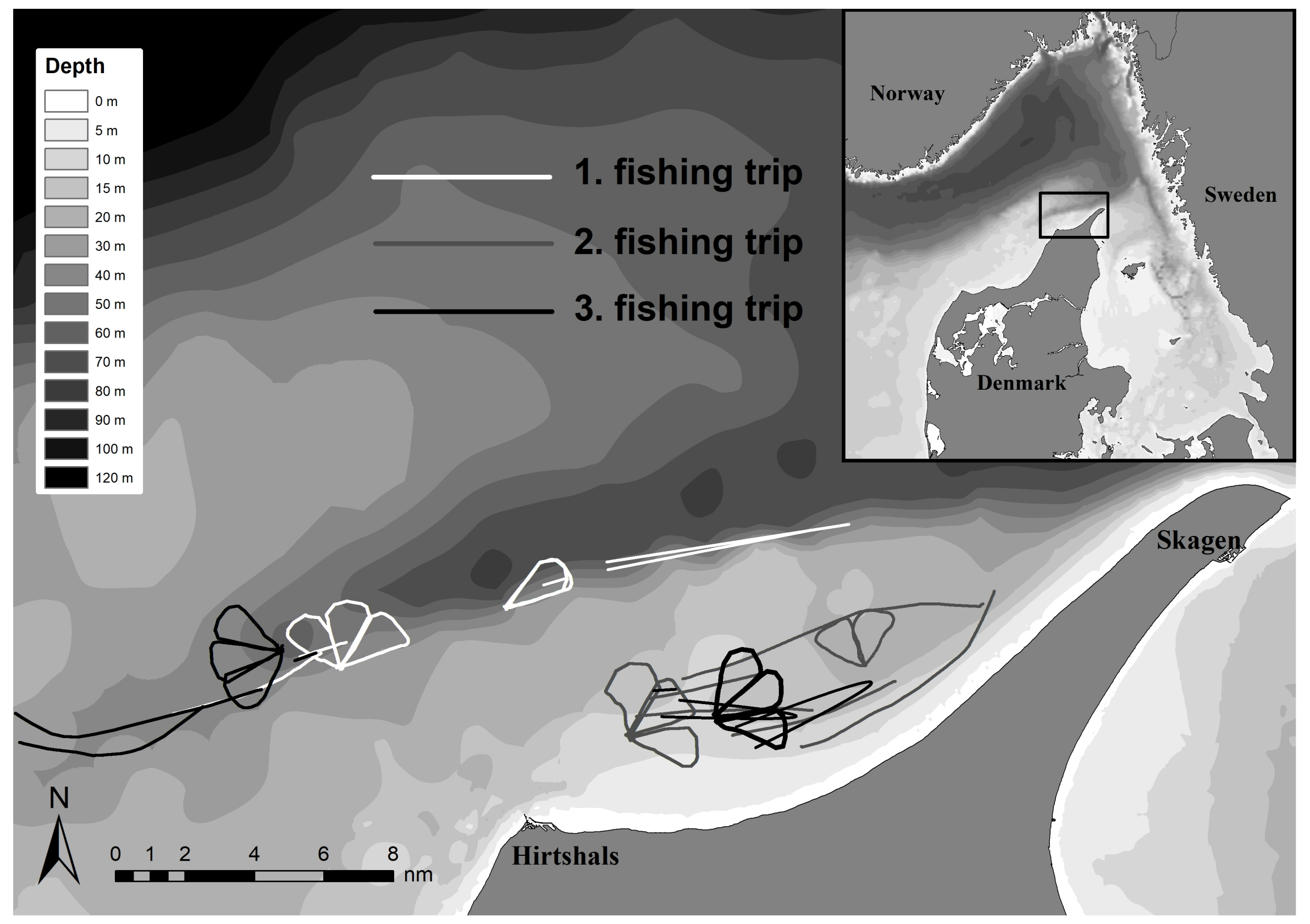




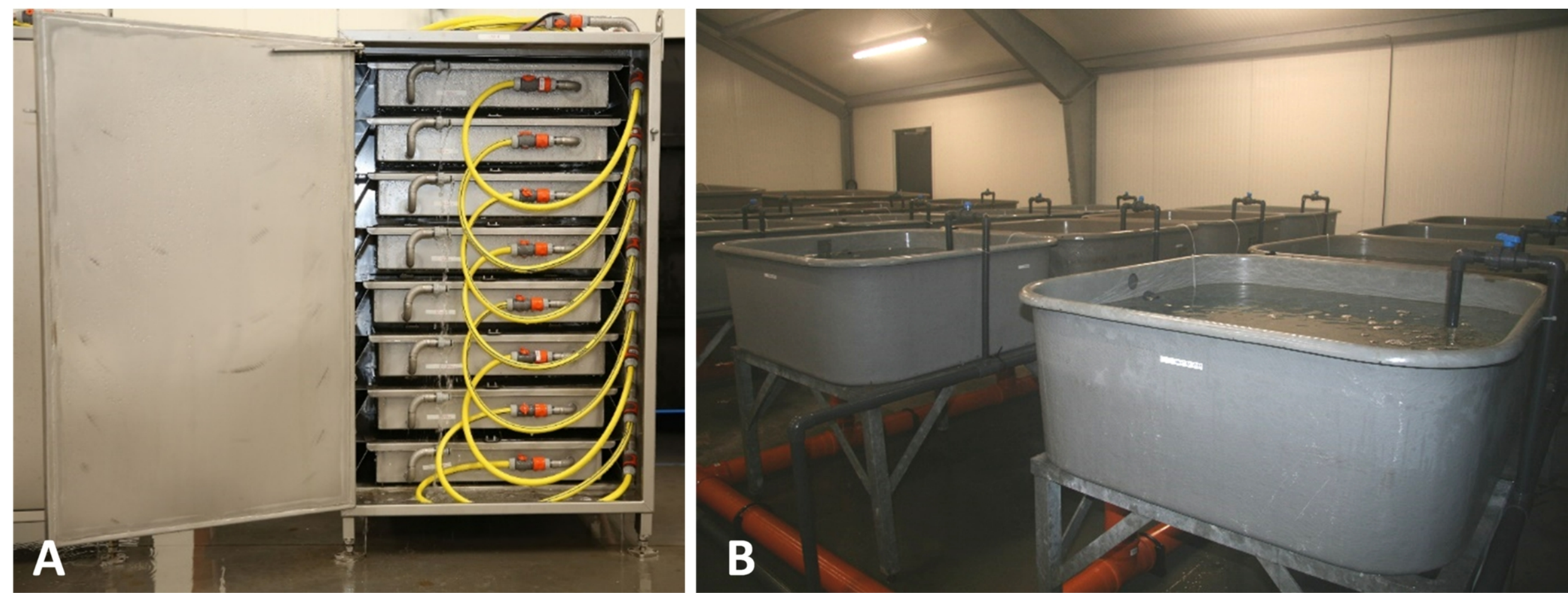




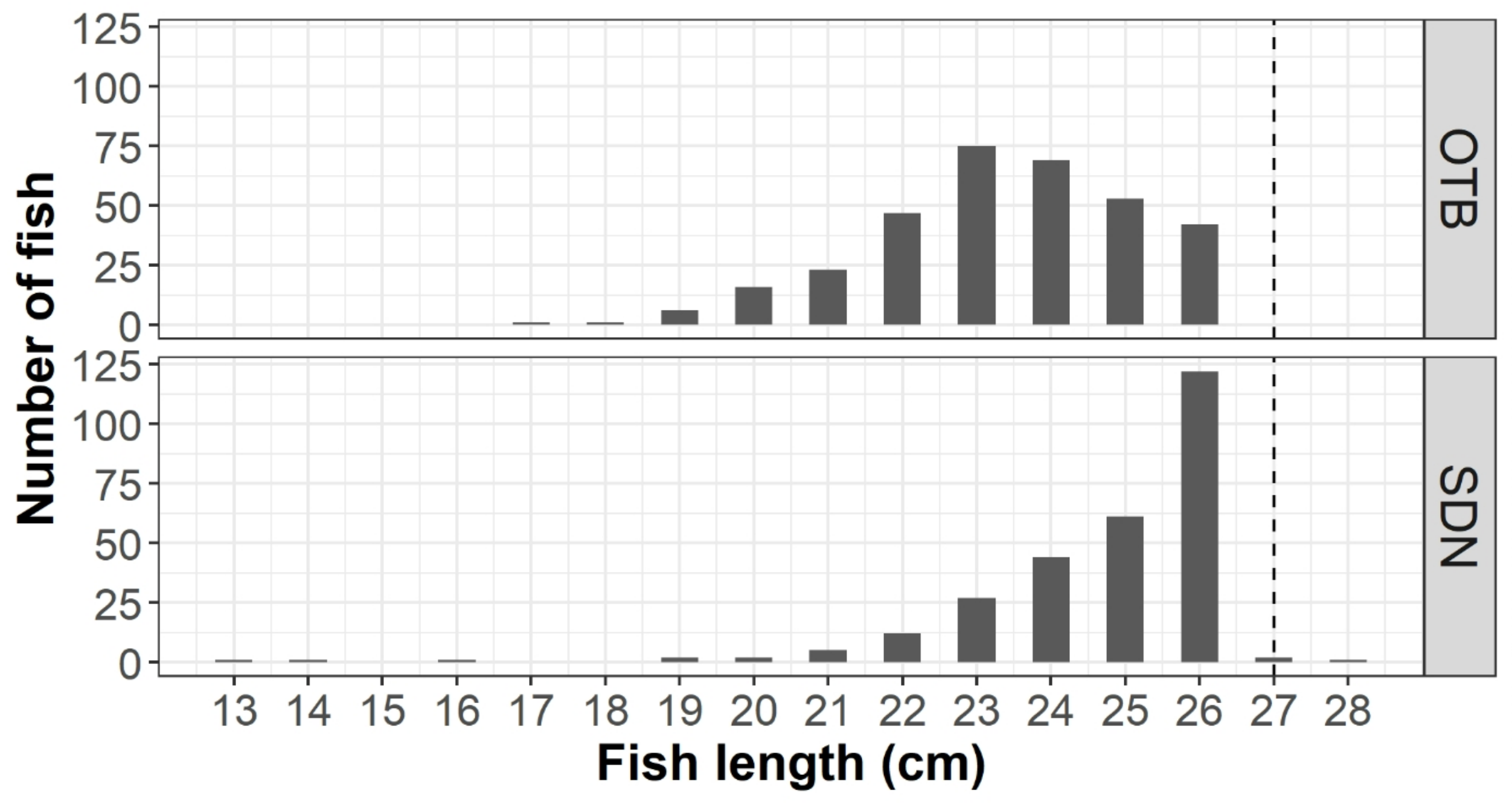


OTB

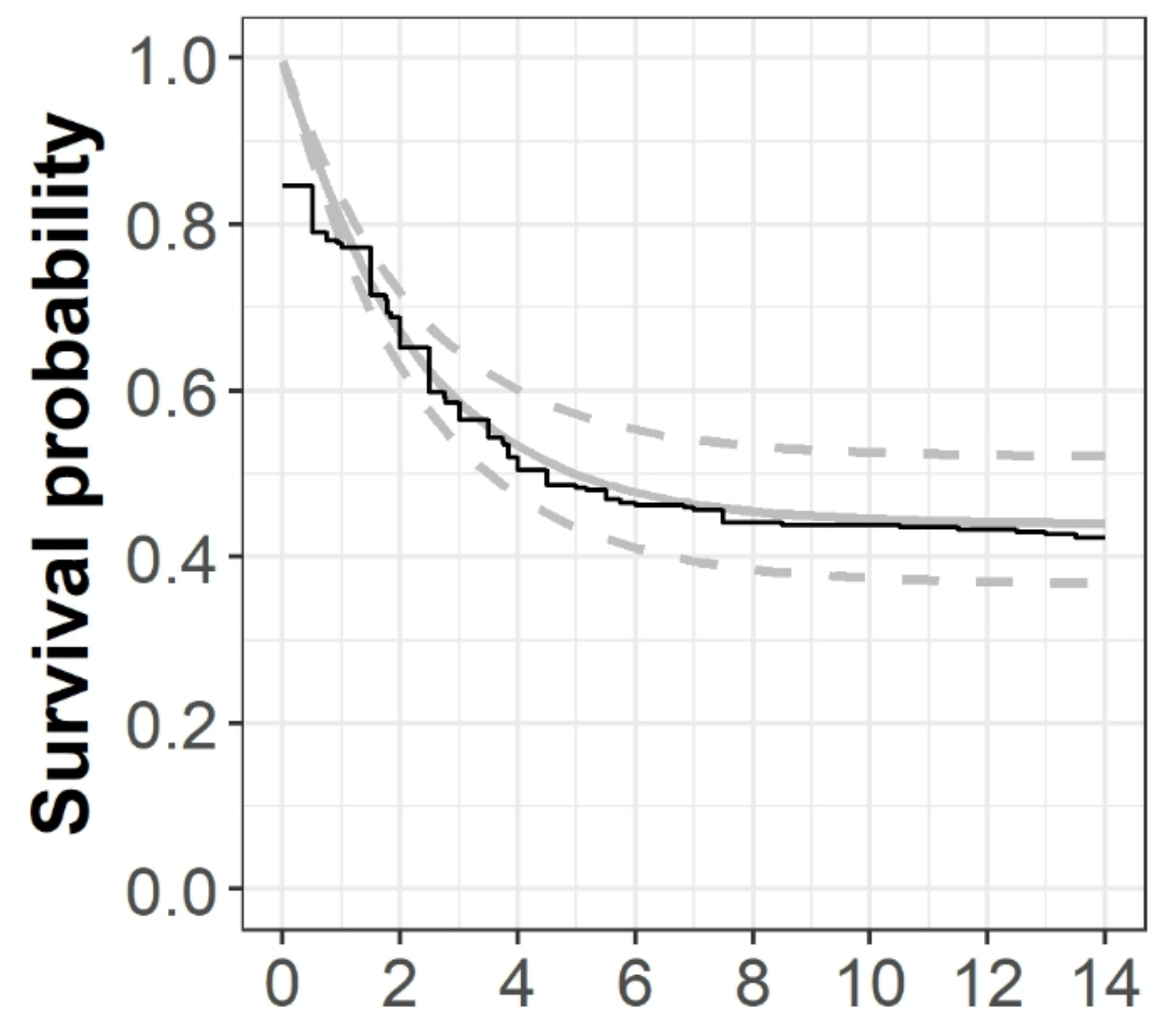

SDN

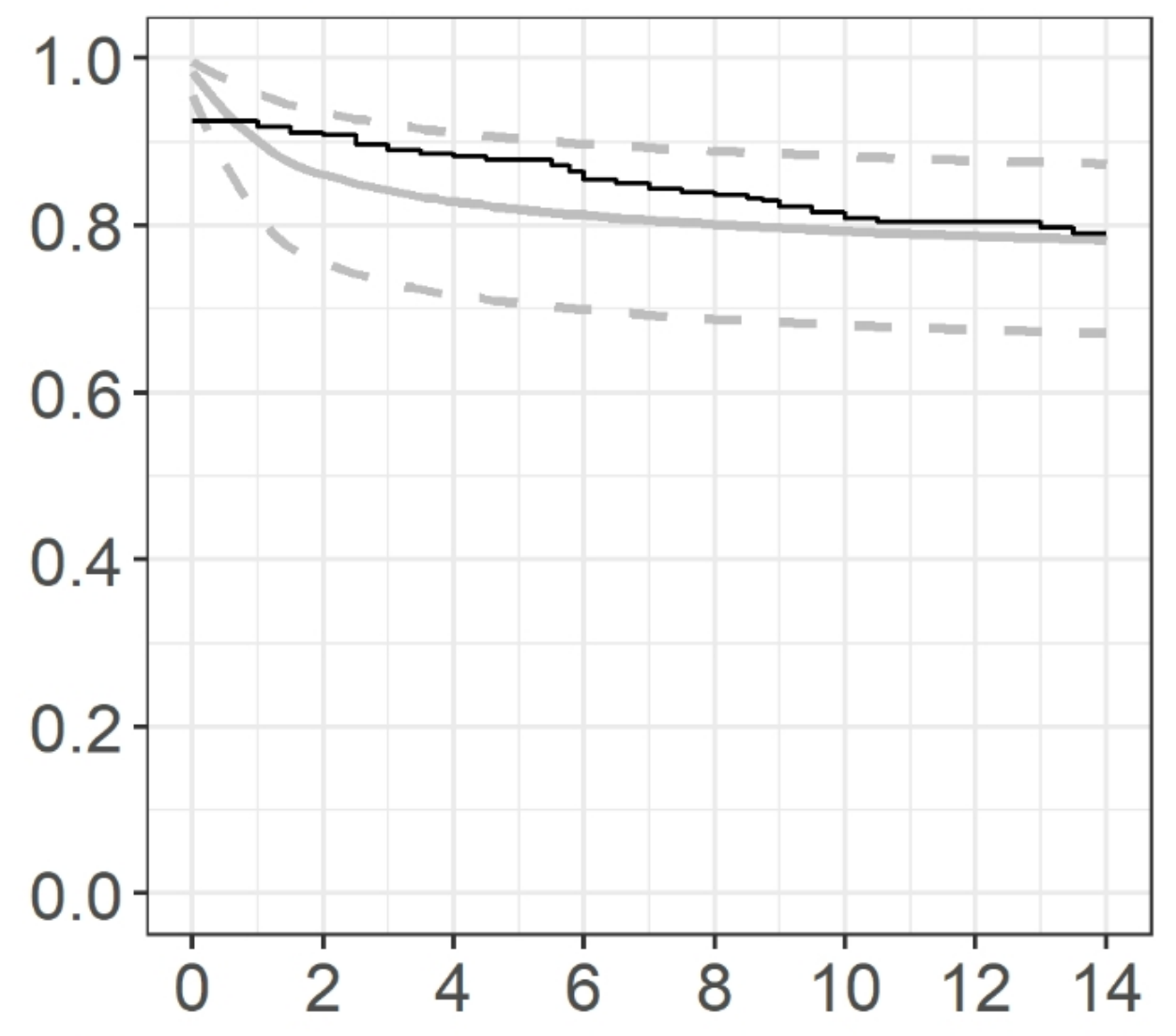

Time (d) 


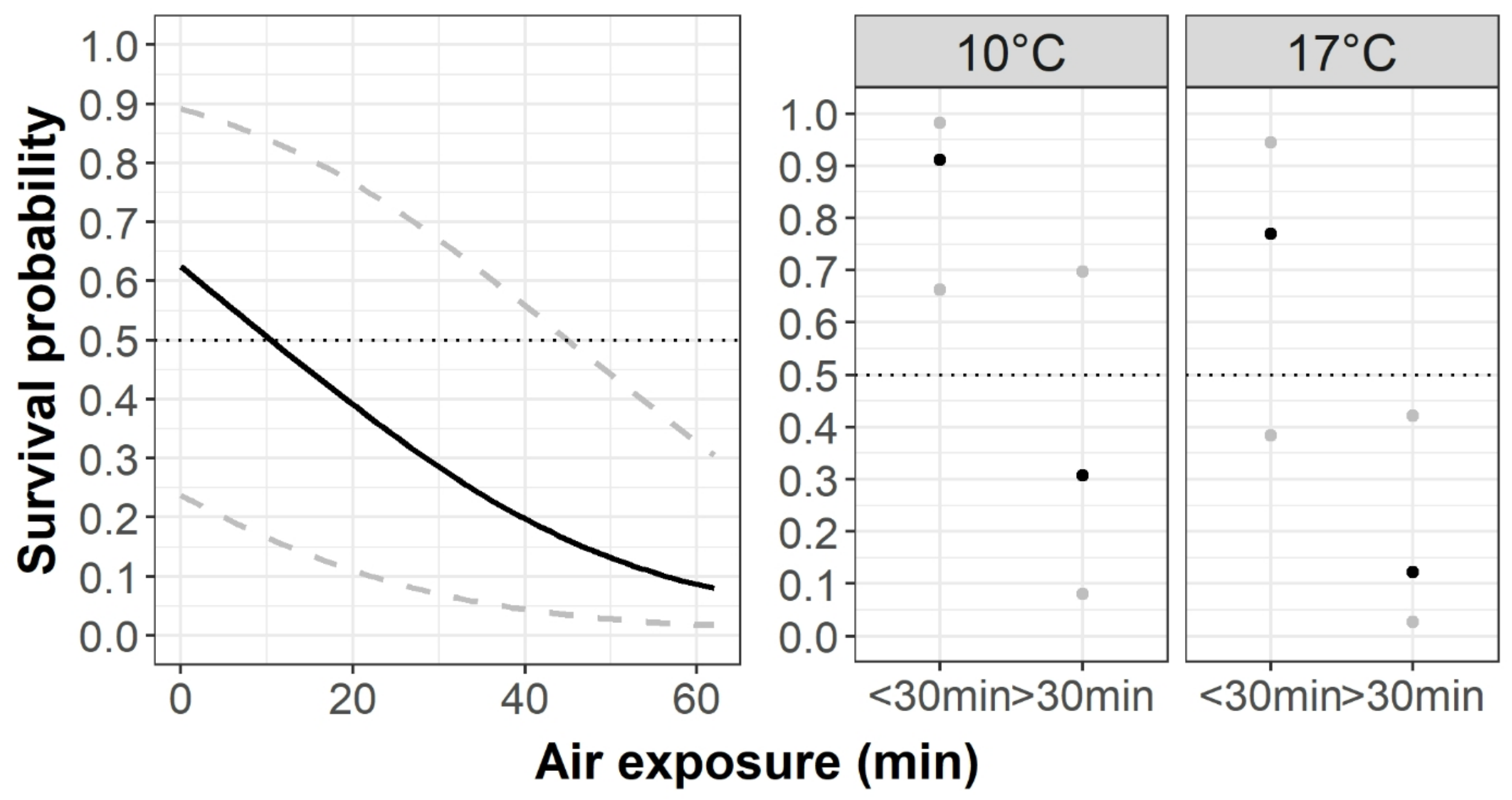


Table 1. Description of the four vitality classes, based on both body movements and damages (Benoit et al., 2010).

\begin{tabular}{lcc}
\hline Vitality class & Description of body movements & Description of damages \\
\hline 1: lively & $\checkmark$ active & $\checkmark$ minor damages \\
2: less lively & $\checkmark$ body movement recognizable & $\checkmark$ visible damages / \\
& & $\checkmark$ hemorrhages \\
& $\checkmark$ apparent damages / \\
3: lethargic & $\checkmark$ no body movement & \\
& $\checkmark$ mouth / operculum movement recognizable & \\
4: moribund & $\checkmark$ no body movement & $\checkmark$ pronounced damages / \\
& $\checkmark$ no mouth / operculum movement & hemorrhages \\
\hline
\end{tabular}


Table 2. Haul characteristics by gear for both experimental and control hauls. Values are given as mean (minimum - maximum). Sea state is given as described by Wileman et al. (1996).

\begin{tabular}{lrrr}
\hline & \multicolumn{2}{c}{ OTB } & \multicolumn{1}{c}{ SDN } \\
\cline { 2 - 3 } & \multicolumn{1}{c}{ control } & experimental & experimental \\
\hline No. of hauls & 6 & 12 & 16 \\
Haul duration $(\mathrm{min})$ & $15(13-16)$ & $141(37-185)$ & $179(150-475)$ \\
Depth $(\mathrm{m})$ & $35(14-59)$ & $34(11-61)$ & $33(12-61)$ \\
Sea state & $2(1-3)$ & $2(1-3)$ & $2(1-4)$ \\
Cloud cover $(\%)$ & $47(10-100)$ & $62(10-100)$ & $59(10-100)$ \\
Air temperature $\left({ }^{\circ} \mathrm{C}\right)$ & $12(5-18)$ & $15(7-20)$ & $14(5-19)$ \\
Bottom temperature $\left({ }^{\circ} \mathrm{C}\right)$ & $14(10-17)$ & $14(10-17)$ & $15(10-17)$ \\
Catch weight $(\mathrm{kg})$ & $59(30-120)$ & $450(65-1509)$ & $283(150-700)$ \\
Air exposure $(\mathrm{min})$ & $0(0-0)$ & $18(0-62)$ & $15(0-45)$ \\
No. of fish & $10(10-10)$ & $28(10-30)$ & $18(4-30)$ \\
Fish length $(\mathrm{cm})$ & $22(14-27)$ & $23(17-26)$ & $25(13-28)$ \\
\hline
\end{tabular}


Table 3. Number of sampled fish (experimental and control) for each haul. Haul identification is given as the gear type abbreviation ('OTB' for the bottom-otter trawl and 'SDN' for Danish seine) and a haul number for each gear. Three control groups (CG) were considered - refer to section 2.4 in the text for additional details.

\begin{tabular}{|c|c|c|c|c|c|c|c|}
\hline \multirow{2}{*}{ Sub } & \multirow{2}{*}{ Date } & \multirow{2}{*}{ Haul } & \multirow{2}{*}{ Experimental fish } & \multicolumn{3}{|c|}{ Controls } & \multirow{2}{*}{ Tota } \\
\hline & & & & CG "acclim." & CG "trawl" & CG 3 "land" & \\
\hline \multirow{9}{*}{1} & \multirow{5}{*}{17.08 . } & OTB1 & 10 & \multirow{2}{*}{10} & \multirow{2}{*}{10} & \multirow{9}{*}{16} & \multirow{9}{*}{284} \\
\hline & & OTB2 & 23 & & & & \\
\hline & & SDN1 & 17 & \multirow{3}{*}{10} & \multirow{3}{*}{ - } & & \\
\hline & & SDN2 & 18 & & & & \\
\hline & & SDN3 & 20 & & & & \\
\hline & \multirow{3}{*}{18.08 . } & OTB3 & 30 & \multirow{2}{*}{10} & \multirow{2}{*}{10} & & \\
\hline & & OTB4 & 30 & & & & \\
\hline & & SDN4 & 30 & 5 & - & & \\
\hline & 21.08. & SDN5 & 30 & 5 & - & & \\
\hline \multirow{9}{*}{2} & \multirow{4}{*}{07.09 . } & OTB5 & 30 & 10 & 10 & \multirow{9}{*}{16} & \multirow{9}{*}{285} \\
\hline & & OTB6 & 30 & 10 & 10 & & \\
\hline & & SDN6 & 15 & 10 & - & & \\
\hline & & SDN7 & 30 & 10 & - & & \\
\hline & \multirow{4}{*}{08.09 . } & OTB7 & 30 & \multirow{2}{*}{10} & \multirow{2}{*}{10} & & \\
\hline & & OTB8 & 30 & & & & \\
\hline & & SDN8 & 23 & \multirow{2}{*}{10} & \multirow{2}{*}{ - } & & \\
\hline & & SDN9 & 4 & & & & \\
\hline & 09.09. & SDN10 & 12 & 5 & - & & \\
\hline \multirow{10}{*}{3} & & OTB9 & 30 & \multirow{2}{*}{10} & \multirow{2}{*}{10} & \multirow{10}{*}{18} & \\
\hline & & OTB10 & 30 & & & & \\
\hline & 09.10 . & SDN11 & 15 & & & & \\
\hline & & SDN12 & 30 & 10 & - & & \\
\hline & & SDN13 & 18 & & & & 200 \\
\hline & & OTB11 & 30 & 10 & & & 300 \\
\hline & & OTB12 & 30 & 10 & 10 & & \\
\hline & 10.10 . & SDN14 & 6 & & & & \\
\hline & & SDN15 & 4 & 10 & - & & \\
\hline & & SDN16 & 9 & & & & \\
\hline
\end{tabular}


Table 4. Distribution of vitality classes over the individuals caught by the bottom-otter trawl ('OTB') and the Danish seine ('SDN') grouped by air exposure.

\begin{tabular}{|c|c|c|c|c|c|c|c|c|}
\hline \multirow{2}{*}{$\begin{array}{l}\text { Vitality } \\
\text { class }\end{array}$} & \multicolumn{4}{|c|}{ OTB } & \multicolumn{4}{|c|}{ SDN } \\
\hline & $0-19 \min$ & 20-39 min & $\geq 40 \mathrm{~min}$ & Total & 0-19 min & 20-39 min & $\geq 40$ min & Total \\
\hline 1 & 6 & 0 & 0 & $6(2 \%)$ & 36 & 3 & 0 & $39(14 \%)$ \\
\hline 2 & 125 & 20 & 4 & 149 (45\%) & 98 & 22 & 0 & $120(43 \%)$ \\
\hline 3 & 48 & 61 & 12 & $121(36 \%)$ & 46 & 41 & 9 & $96(34 \%)$ \\
\hline 4 & 2 & 24 & 31 & $57(17 \%)$ & 1 & 7 & 18 & $26(9 \%)$ \\
\hline Total & 181 & 105 & 47 & $333(100 \%)$ & 181 & 73 & 27 & $281(100 \%)$ \\
\hline
\end{tabular}


Table 5. The relative importance of each explanatory variable for the bottom-otter trawl ('OTB') and the Danish seine ('SDN'). Each variable is present in 3584 models out of a total number of 4096 models. A value close to 1 indicates that the explanatory variable is present only among the best models according to AIC.

\begin{tabular}{lll}
\hline & OTB & SDN \\
\hline Air exposure & 1.00 & 1.00 \\
Fish length & 0.52 & 0.64 \\
Air temperature & 0.47 & 1.00 \\
Bottom temperature & 0.58 & 0.96 \\
\hline
\end{tabular}


Table 6. Models fit to the bottom-otter trawl ('OTB') and the Danish seine ('SDN') data with a relative difference in AIC ('dAIC') $<2$, interpreted as having similar support in the data, together with their Akaike weight. Ratios of Akaike weights (evidence ratio) provide quantitative information about the support for one model relative to the first model. The chosen model for each gear is shown in bold, with 'Exposure' for air exposure, 'Length' for fish length, 'Air' for air temperature and 'Bottom' for bottom temperature.

\begin{tabular}{lllllll}
\hline & Explanatory variables for & & & & \\
Rank & $\alpha$ & $\gamma$ & $\pi$ & dAIC & Weight Evidence \\
\hline $\boldsymbol{O T B}$ & & & & & & \\
$\mathbf{1}$ & - & - & Exposure & $\mathbf{0 . 0 0}$ & $\mathbf{0 . 0 8}$ & - \\
2 & - & - & Exposure, Bottom & 0.42 & 0.06 & 1.2 \\
3 & - & - & Exposure, Length & 1.19 & 0.04 & 1.8 \\
4 & - & - & Exposure, Air & 1.85 & 0.03 & 2.5 \\
5 & - & - & Exposure, Length, Bottom & 1.89 & 0.03 & 2.6 \\
$\boldsymbol{S D N}$ & & & & & & \\
1 & Exposure, Air, Bottom & - & Exposure, Bottom & 0.00 & 0.05 & - \\
2 & Exposure, Air, Bottom & - & Exposure, Air, Bottom & 1.29 & 0.03 & 1.9 \\
3 & Exposure, Air, Bottom & - & Exposure, Length, Bottom & 1.67 & 0.02 & 2.3 \\
4 & Exposure, Length, Air, Bottom & - & Exposure, Bottom & 1.77 & 0.02 & 2.4 \\
$\mathbf{5}$ & Exposure, Air & - & Exposure, Bottom & $\mathbf{1 . 9 6}$ & $\mathbf{0 . 0 2}$ & $\mathbf{2 . 7}$ \\
\hline
\end{tabular}


Table 7. Estimated regression parameters for $\alpha, \gamma$ and $\pi$ of the chosen model for each gear, i.e., the bottom-otter trawl ('OTB') and the Danish seine ('SDN').

\begin{tabular}{llll}
\hline Parameter & $\alpha$ & $\gamma$ & $\pi$ \\
\hline $\boldsymbol{O T B}$ & & & \\
Intercept & 0.02 & 1.00 & 0.59 \\
Air exposure & - & - & 0.67 \\
$\boldsymbol{S D N}$ & & & \\
Intercept & 0.01 & 1.00 & 0.17 \\
Air exposure $>30 \mathrm{~min}$ & 8.82 & - & 0.96 \\
Air temperature & 2.70 & - & - \\
Bottom temperature & 1.32 & - & 0.60 \\
\hline
\end{tabular}


Table 8. Observed survival is given for the three control groups ('CG') with the total number of individuals sampled in brackets $(n)$ - refer to section 2.4 in the text for additional details on the different control groups. Estimated overall survival is given for the experimental groups with the $95 \%$-confidence interval in brackets for the bottom-otter trawl ('OTB') and the Danish seine ('SDN').

\begin{tabular}{lll}
\hline Group & & Survival \\
\hline Observed & & \\
Control & CG “acclim.” & $0.84(n: 125)$ \\
& CG "trawl” & $0.87(n: 60)$ \\
& CG "land" & $1.00(n: 43)$ \\
Estimated & & \\
Experimental & OTB & $0.44(0.37-0.52)$ \\
& SDN & $0.78(0.67-0.87)$ \\
\hline
\end{tabular}

